\title{
Best practice recommendations for the use of fully implanted telemetry devices in pinnipeds
}

\author{
Markus Horning ${ }^{1,2^{*}}$ (D), Martin Haulena ${ }^{3}$, Pamela A. Tuomi ${ }^{1}$, Jo-Ann E. Mellish' ${ }^{1}$, Caroline E. Goertz' \\ Kathleen Woodie ${ }^{1}$, Rachel K. Berngartt ${ }^{4}$, Shawn Johnsonn ${ }^{5}$, Courtney R. Shuert ${ }^{6}$, Kristen A. Walker ${ }^{7}$, \\ John P. Skinner ${ }^{1}$ and Peter L. Boveng ${ }^{8}$
}

\begin{abstract}
Electronic telemetry devices have enabled many novel and important data collection and experimental opportunities for difficult to observe species. Externally attached devices have limited retention and may affect thermoregulation, energetics, social and reproductive behavior, visibility, predation risk and entanglement. Internally placed, surgically implanted devices can mitigate some of these effects and may open additional experimental opportunities. However, improper implementation can significantly affect animals and data. From a review of recent studies using fully implanted tags and studying their effects, we present 15 specific best practice recommendations for the use of such tags in pinnipeds. Recommendations address issues including device size, coating and sterilization, implantation surgery and effect assessment, within the framework of the Three R's: Reduction, Refinement, Replacement. While developed for pinnipeds, these recommendations could apply to other aquatic mammals and vertebrates and to partially implanted or even external tags.
\end{abstract}

Keywords: Biotelemetry, Implant, Subcutaneous, Intraperitoneal, Marine mammal, Surgery, Reduction, Refinement, Replacement

\section{Background}

Electronic telemetry devices have been used effectively to track location and movement and to monitor foraging and reproductive behavior as well as the physiological and reproductive state of terrestrial, avian and marine vertebrates for more than five decades $[1,2]$. This has been particularly useful for difficult to observe taxa such as marine vertebrates [3-6]. Most commonly, such devices are externally attached, resulting in limited monitoring durations for animals that molt or shed on a regular basis. Furthermore, external devices can affect social, reproductive and movement behavior, or the energetics of locomotion and thermoregulation, and may increase the risk of entanglement, visibility and predation [5, 711]. Surgically implanted internal devices ${ }^{1}$ may reduce some of these effects, allow longer-duration deployments and the use of additional sensors, but may also result in substantial and potentially catastrophic effects if improperly implemented. Recent discussions $[8,12]$ and working group reports on 'refinements in telemetry procedures' have highlighted that 'Telemetry is often presented as a refinement, in that it can reduce or eliminate stress caused to animals (e.g., by restraint), but it is vital to remember that telemetry, like all other procedures on animals, also needs to be refined' [13].

*Correspondence: markush@alaskasealife.org

1 Alaska SeaLife Center, 301 Railway Avenue, Seward, AK 99664-1329, USA Full list of author information is available at the end of the article

\footnotetext{
${ }^{1}$ Defined here as any active electronic monitoring or transmitting device that once fully implanted into any part of the body does not break the integument.
} 


\section{Existing recommendations by societies and recent workgroups}

In the USA federal funding agencies have adopted the policy instituted by the Public Health Service on the humane care and use of laboratory animals, under the Animal Welfare Act. This policy requires research to be compliant with the Guide for the Care and Use of Laboratory Animals [14]. The Guide provides important ethical guidance on principles of humane animal research with a focus on biomedical laboratory settings, but few specific procedural recommendations are applicable to research involving wildlife [15]. Recognizing these shortcomings, the US National Science Foundation requested professional societies to develop taxon-specific guidelines suitable for wild species and field work [15]. Most applicable professional societies, the Guide and the Joint Working Group on Refinement [13] point out the need to consider and assess the impact of external and internal telemetry devices on research subjects. However, few consistent guidelines exist across or within taxa with respect to shape, relative size, mass and volume of devices, with respect to surgical procedures or the parameters that should be applied in considering the impact of devices [8].

The American Fisheries Society provides no recommendations for implanted telemetry devices in fishes, of any kind [16]. Much of the recent work (since the late 1990s) assessing the effects of implanted devices on wild animals has been conducted on anadromous fish, due to management concerns and regulatory status of some species [17-21]. Authors have repeatedly challenged the anecdotal, yet never formalized ' $2 \%$ rule' for fish based on the demonstrated absence of negative effects on swimming energetics, growth and survival for relative sizes of tags up to $6.7 \%$ of body mass $[17,19,22]$. The American Society of Ichthyologists and Herpetologists suggests an upper size limit of $10 \%$ of body mass on an anecdotal basis for implanted devices in amphibians and reptiles, but points out that sizes between 1 and $6 \%$ are often achievable [23]. The Ornithological Council quotes studies suggesting that external or internal telemetry transmitters in birds should not exceed 5\% of a subject's body mass, but also points out that this value or a less commonly applied 3\% threshold are completely arbitrary and that multiple conflicting studies found both presence and absence of effects of tags in the 1-3\% mass range on survival [24]. Guidelines by the American Society of Mammalogists [25] only vaguely recommend external devices not exceed $5-10 \%$ of individual body mass but do not (separately) consider implanted devices. Finally, the Society for Marine Mammalogy provides no specific recommendation for external or internal tags, but encourages the conduct and publication of studies of short-term and long-term effects of tags [26]. A recent report by the Joint Working Group on Refinement [13] does not provide specific recommendations, but does point out that 'smaller is better', and that adding mass can have a significant physiological impact and can alter body mass set points. The report also references multiple studies that have shown that animals carrying devices can incur measurable and significant energetic costs of transportation, of a magnitude ranging from about half of the mass percentage (i.e., a tag adding $5 \%$ to the mass of a mammal may result in an added energetic burden of $2.5 \%$ ) to as high as double the mass percentage in flying birds (see also [27-29]).

\section{Implanted telemetry devices in birds}

Barron et al. [30] evaluated 84 published studies using external or internal devices on birds for reported presence or absence of specific effects. While most effects were small in magnitude (e.g., device-induced preening), the most consistently reported effect of devices in this meta-analysis was increased energy expenditure and reduced nesting likelihood. Attachment methods requiring anesthesia (i.e., anchored and implanted devices) had the highest reported incidence of mortality, while external devices were the only type resulting in reported 'device-induced behaviors' Furthermore, device effects were more pronounced in relation to uncaptured controls than 'procedural controls' (those handled and temporarily captive in the same manner as tagged individuals) suggesting some of the observed effects were due to handling and captivity. However, in a subsequent meta-analysis of 55 studies on 49 species of birds, White et al. [31] specifically compared effects between external and fully implanted devices. This meta-analysis revealed consistently negative effects of externally attached devices, while no consistent effects were reported for implants. The authors concluded that internal devices are preferable to external devices provided that risks associated with anesthesia and surgery can be mitigated. In diving or aquatic birds, Culik and Wilson [28] found energetic and behavioral effects of both external ( $n=5$ animals) and internal tags ( $n=2$ animals) on Adelie penguins (Pygoscelis adeliae). However, sample sizes were extremely small and the implanted devices were connected to internal electrocardiography electrode wires and were further secured to the musculature via sutures. Such wires and fixing sutures may increase the likelihood of device effects. Beaulieu et al. [32] compared the effects of external ( $n=10$ animals $)$ and internal $(n=6$ animals $)$ tags on the foraging behavior of Adelie penguins. They noted altered foraging behavior in animals carrying internal 
tags, but none in animals carrying external tags. However, the implants were secured with sutures, and only a single foraging trip per animal was observed, which for implanted birds occurred less than 6 days after surgery. Interestingly, the meta-analysis conducted by White et al. [31] showed that most device effects reported tended toward zero with increasing sample sizes, suggesting that some reported effects may be outliers, or that methods improve with experience of investigators. The absence of a proportional mass effect (i.e., bigger tags are associated with a greater effect magnitude) has been used to illustrate the arbitrary nature of mass-percent device size thresholds $[13,29,30]$.

\section{Fully implanted telemetry devices in aquatic mammals}

Within aquatic mammals, fully implanted telemetry devices (subcutaneous ${ }^{\mathrm{S}}$, intraperitoneal ${ }^{\mathrm{I}}$ ) have been tested or used in sea otters ${ }^{\mathrm{I}}$ (Enhydra lutris), Eurasian otters $^{\mathrm{I}}$ (Lutra lutra), North American river otters ${ }^{\mathrm{I}}$ (Lontra canadensis), nutria ${ }^{\mathrm{I}}$ (Myocastor coypus), beavers ${ }^{\mathrm{I}}$ (Castor canadensis), muskrat ${ }^{\mathrm{I}}$ (Ondatra zibethicus), polar bears ${ }^{\mathrm{S}}$ (Ursus maritimus), harbor seals ${ }^{\mathrm{S}, \mathrm{I}}$ (Phoca vitulina), Northern elephant seals ${ }^{\mathrm{S}}$ (Mirounga angustirostris), California sea lions ${ }^{\mathrm{S}, \mathrm{I}}$ (Zalophus californianus) and Steller sea lions ${ }^{\mathrm{I}}$ (Eumetopias jubatus) [33-53].

As previously summarized [43], several studies that used free-floating intra-abdominal implants reported on the effects of implants on reproduction in aquatic mammals. Reid et al. [33] specifically studied reproductive effects of intraperitoneal implants in North American river otters over one to two reproductive cycles. In seven adult females, they observed 12 possible pregnancies that resulted in eight litters. They concluded that the implants did not interfere with reproduction. Hernandez-Divers et al. [38] also concluded that implants did not affect survival or reproductive potential in North American river otters. Bohrman et al. [45] reported on successful reproduction in one single North American river otter with an intraperitoneal implant. FernandezMoran et al. [39] reached the same conclusion in a study of Eurasian otters. Nolfo and Hammond [42] implanted VHF transmitters intraperitoneally into 20 adult nutria, nine males and 11 females. All females were pregnant. One female aborted her near-full-term litter within one day of surgery and prior to release, likely as a result of anesthesia. The authors found no evidence of morbidity or infection. They concluded that the implants did not interfere with reproduction. Monnett and Rotterman [37] intraperitoneally implanted devices into 19 adult female sea otters that were deemed pregnant at time of implantation based on abdominal palpation. Seventeen of the 19 pupped successfully. They could not determine whether the two remaining sea otters were misclassified as pregnant, had stillbirths, aborted prematurely or whether the pups died after birth. Bodkin et al. [40] intraperitoneally implanted two telemetry devices into each of 21 sea otters: one VHF transmitter and one time-depth recorder. The animals were subsequently recaptured, and the archival data loggers were surgically removed. Tags were recovered from 14 animals that were recaptured after two months. One animal was found dead after four years. No reasons for mortality were reported. One pregnant female that was implanted was subsequently recaptured with a pup. Subsequent studies reported on data derived from intraperitoneal tags implanted into sea otters, but possible effects were not investigated or reported [47, 48].

\section{Fully implanted telemetry devices in pinnipeds}

Lander et al. [41] tested four different kinds of subcutaneous implants in 10 harbor seals with varied results. Animals with resin-encased transmitters developed fluid pockets and mucopurulent discharge, whereas wax-coated devices elicited no such response. $\mathrm{CBC}$ and serum biochemistry values were within normal ranges within one week of surgery for nine of the 10 animals. The authors concluded that wax-coated implants were preferable for long-term subcutaneous deployments. Green et al. [44] conducted trial implantations of subcutaneous heart rate data loggers with electrocardiography wires into three Northern elephant seals and three California sea lions. All animals recovered uneventfully from the surgery, but the elephant seals then developed a 'substantial inflammatory response' and the devices had to be removed. Blundell and collaborators [50] subcutaneously implanted wax-coated VHF transmitters (also used in the Lander study) in 277 harbor seals in Alaska. The transmitters were programmed to send an altered signal when tag temperature dropped below $27^{\circ} \mathrm{C}$, indicating possible mortality or tag extrusion. Animals were released within hours of surgery, and no consistent postoperative monitoring besides automated VHF tracking was reported. No altered signals were detected during the study that could be attributed to an actual mortality. Four isolated tags were recovered, and one animal was recaptured after one year with a partially extruded tag. Manugian et al. $[51,52]$ reported on the use of wax-coated subcutaneous VHF implants in nine harbor seals closely monitored up to three weeks before release, and another 32 released immediately after implantation. No complications were reported from this study, though the authors do refer to one instance from a prior study (it is unclear which study they refer to) where a subcutaneously implanted waxcoated tag was observed migrating out of a juvenile harbor seal about nine months after implantation. 


\section{Life-long implanted vital rate transmitters}

In 2004, Horning-in collaboration with Wildlife Computers, Inc. (Redmond, WA)-completed the development of a new implantable telemetry device, the life history transmitter (LHX tag) [54]. LHX tags were specifically designed for vital rate telemetry in California and Steller sea lions. The cylindrical tags with hemispherical ends (42 mm diameter, $128 \mathrm{~mm}$ length, $202 \mathrm{ml}$ volume, $118 \mathrm{~g}$ mass, $0.87 \mathrm{~N}$ buoyancy) are intraperitoneally implanted [43] and record data throughout the life of the host. Summary data are only transmitted via the Argos satellite system postmortem, after the positively buoyant tags are liberated from decomposing, dismembered or digested carcasses. In 2014, development of the second-generation LHX2 tag was completed (with Wildlife Computers, Inc.). LHX2 tags are smaller (Fig. 1, $33 \mathrm{~mm}$ diameter, $97 \mathrm{~mm}$ length, $79 \mathrm{ml}$ volume, $54 \mathrm{~g}$ mass, $0.26 \mathrm{~N}$ buoyancy) and can be programmed to evaluate temperature patterns for parturition events. LHX tags can be used to determine date, location and causes of mortality $[49,55]$, and also age at primiparity and lifetime number of pups born if deployed in pre-parous females.

Horning, Mellish and collaborators implanted single or dual intraperitoneal LHX tags in 49 otariids from 2004 to 2014 (4 California sea lions and 45 Steller sea lions [43, $46,49,54,55])$. For the first two deployments in each species, single tags were used. Subsequently, two tags per animal were used to increase and estimate data return probability. For initial deployments animals were held in extended captivity up to eight weeks after surgery prior to release to allow comprehensive assessments of postoperative effects including physiological changes [56-59], stress response [60], as well as behavioral indicators of pain $[61,62]$. Following release, all animals were tracked via externally attached satellite telemetry transmitters for periods ranging from one week to four months $[57,63]$. Following surgery, the study animals exhibited changes in behaviors that are indicative of discomfort ${ }^{2}$ or pain ${ }^{3}$ [43]. The proportion of time spent standing and in a back arch increased, and the proportion of time spent lying on the ventral side where the incision was located decreased. Peak changes occurred for days 1-3 after surgery, and changes diminished but remained above pre-surgical levels at days 10-12. The proportion of time spent in locomotion decreased for days $1-3$, but was at pre-surgery levels for days 10-12 [61]. Surgical wounds appeared

\footnotetext{
${ }^{2}$ Defined here as a non-nociceptive allostatic load potentially affecting wellbeing (e.g., dyspepsia-including nausea and dysmotility, tachycardia, hypoor hypertension, hypo- or hyperthermia, hyperventilation).

${ }^{3}$ Defined as an unpleasant sensory and emotional experience associated with actual or potential tissue damage or described in terms of such damage [64].
}

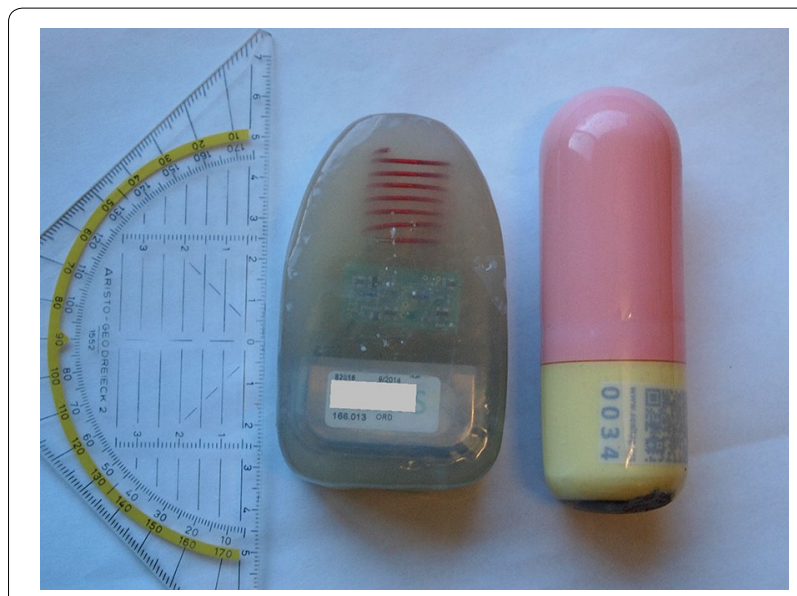

Fig. 1 A second-generation LHX2 implantable Argos-compatible satellite transmitter (Wildlife Computers Inc., Redmond, WA) is shown on the right. Exterior dimensions are $97 \mathrm{~mm}$ length by $33 \mathrm{~mm}$ diameter. The tag mass is $54 \mathrm{~g}$; buoyancy is $0.26 \mathrm{~N}$. The device is coated in EpoTek 302-3M resin, a material certified under the USP Class 6 standard for biological reactivity. The $\mathrm{QR}$ code links to information on the tag, project and rewards for return. A VHF radio transmitter (ATS Inc., Isanti, MN) is shown in the middle. Exterior dimensions are $90 \mathrm{~mm}$ length by $59 \mathrm{~mm}$ width by $30 \mathrm{~mm}$ thickness. The transmitter mass is $150 \mathrm{~g}$; buoyancy is $-0.27 \mathrm{~N}$. The device is cast in an unspecified electrical resin and coated with an unspecified USP Class 6-certified material (๑) Markus Horning)

healed upon external, visual examination and palpation, and the initial postoperative elevation of blood analytes associated with the inflammatory response had returned to pre-surgical levels after five weeks [43, 57, 59]. From these observations, the authors derived a 45-day postoperative survival study inclusion criterion. All 49 otariids had survival confirmed beyond the 45-day postoperative study inclusion criterion, whether released after one, two or up to eight weeks following surgery $[49,57]$. These studies also demonstrated that transmitter implantation has no detectable effect on postrelease movement and diving behavior as compared to animals that also underwent temporary captivity but without LHX tag implants [57]. Captivity may have a small but detectable, shortterm ( 2 weeks) effect on postrelease diving behavior in comparison to wild animals that did not undergo temporary captivity [63]. Long-term survival beyond the attachment of external transmitters was compared between implanted animals and non-implanted controls that did not undergo captivity, based on a mark-resight study design using hot-iron branding. No differences in survival patterns between implanted animals and nonimplanted controls were detectable between the ages of 14 months to five years [65]. From the ratio of dual- to single-tag data returns in 20 mortalities detected to date (through 2016) and in 10 dual-tag carcass simulations, 
data return probability was estimated at $>0.98$ [49]. Of the 17 female Steller sea lions in that study implanted with single ( $n=1$ animal) or dual tags ( $n=16$ animals) between 2005 and 2014, eight animals have died by predation [49], and nine remain alive. Of these, only three have reached a reproductive age. The first female implanted with a single LHX tag in 2005 at the age of 1.4 years was confirmed with a suckling juvenile in 2013 at age nine (see Fig. 2) and with a suckling pup in 2015 at age 11 (L. Jemison, ADFG pers. comm.). The second oldest female was implanted with dual LHX tags in 2008 at the age of 1.8 years, and a live birth was confirmed via a remote video observation system in the region in 2013, at the age of seven years (J. Maniscalco, pers. comm). The animal was resighted as recently as June 2016, but the reproductive status could not be ascertained at that time. The third oldest female was last sighted in 2016 at the age of seven and not associated with a pup at that time.

In 2014, Horning et al. [53] abdominally implanted single second-generation LHX2 tags into three recently rehabilitated harbor seal pups (Fig. 3). All three animals exhibited the expected inflammatory response but recovered well. Wound healing and the acute phase of the inflammatory response were resolved by six weeks after surgery. After that time, all blood analytes were within ranges observed in non-implanted animals [53]. Survival was confirmed, and all three animals tracked for about one year after release through external satellite transmitters [53].

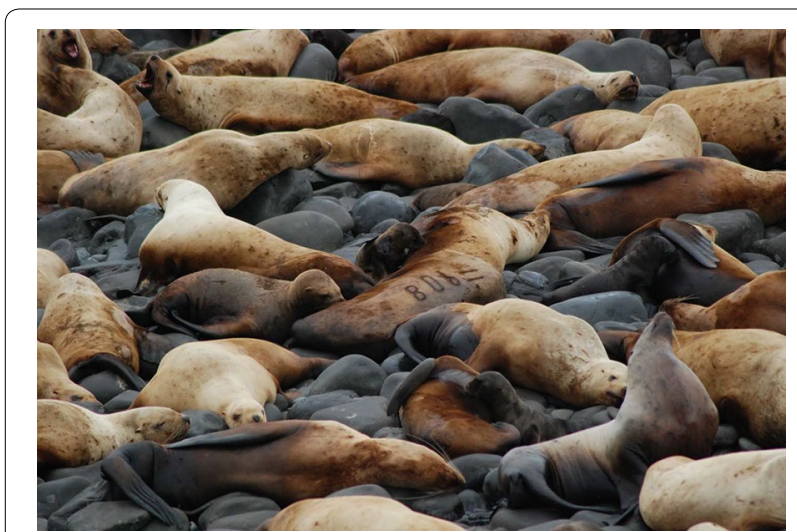

Fig. 2 Adult female Steller sea lion marked with brand $=908$. This female received a single first-generation LHX implant on September 27, 2005, and was released on November 22, 2005. The female was approximately 1.4 years old when released. This image with the female nursing her yearling offspring was taken on July 13, 2013, with the female just over nine years old. The female was confirmed with a newborn pup in 2015 at the age of 11 years and last resighted in 2016 at the age of 12 years ( $\odot$ AK Dept. of Fish \& Game, photographer Betsy Van Burgh, pursuant to NMFS permit no. 14325)

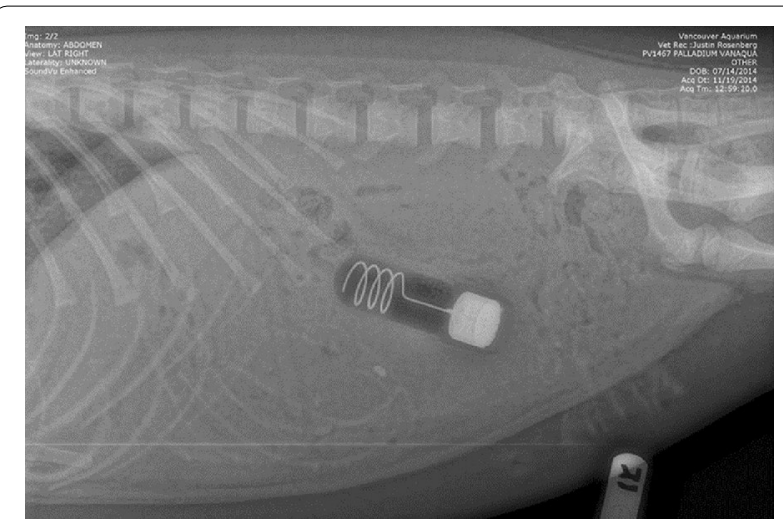

Fig. 3 Lateral abdominal radiograph of a 125-day-old female harbor seal with a body mass of $30.7 \mathrm{~kg}$ showing a second-generation LHX2 tag. The tag was implanted 79 days earlier, at a body mass of $12.4 \mathrm{~kg}$ as described in Horning et al. [53] (๑ Vancouver Aquarium, DFO permit, Vanc. Aq. ACC no. 2012-06)

In September of 2016, Horning, Boveng and collaborators implanted dual second-generation intraperitoneal LHX2 tags into 10 subadult and adult wild harbor seals in the Aleutian Islands (Horning et al. unpubl. data, Fig. 4). The animals underwent implant surgery within $2-4 \mathrm{~h}$ of capture and were released $2-3 \mathrm{~h}$ after recovering from anesthesia. Surgeries were conducted as described in Horning et al. [53], within a portable surgical container setup on the back deck of the 33-m research support vessel R/V Norseman. All ten animals also received two external satellite transmitters for postrelease studies of movement and dive behavior. All ten animals were successfully tracked for a minimum of 60 days after release, and this tracking effort is continuing (Boveng et al. unpubl. data). These ten animals represent the first instance of at-sea intra-abdominal implantation surgeries with same-day release, in a pinniped.

\section{Best practice recommendations}

In the absence of specific guidelines, researchers have relied primarily on select studies in justifying experimental and device designs. Here we propose 15 specific recommendations to guide investigators and regulators in preparing and reviewing applications of fully implanted tags (FITs) in pinnipeds, based on our collective experience over the past decades. Due to their very small size, extensive use and wide acceptance in veterinary practice, we specifically exclude passive devices (PIT tags) from these considerations. Our recommendations are not societal guidelines and should supplement rather than supersede many previously published recommendations on animal research, capture, handling, sampling, captivity and telemetry $[8,12,13]$. 


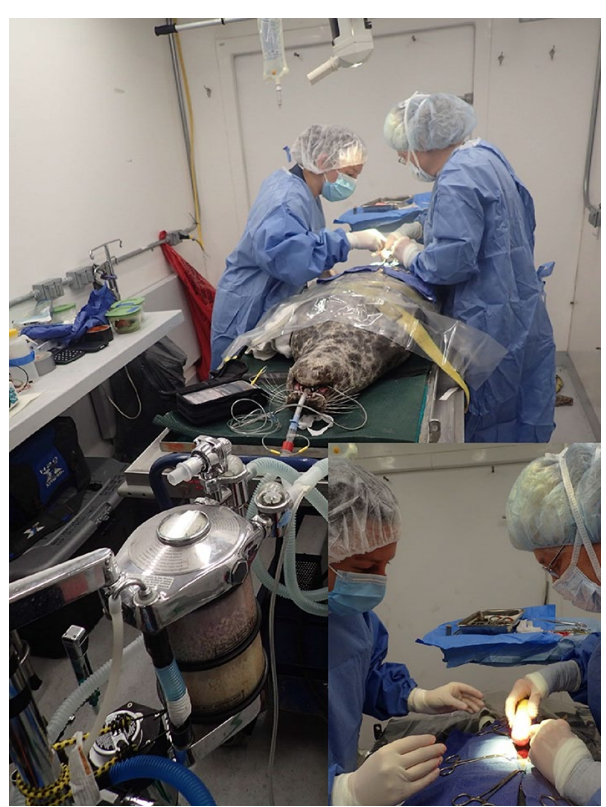

Fig. 4 Abdominal implantation surgery is being conducted under standard, aseptic procedures utilizing sterile instruments, surgical garb and isoflurane gas for general anesthesia. A harbor seal is placed on an insulated, elevated table in dorsal recumbency and the surgical area covered in a sterile, fenestrated drape. Positive pressure mechanical ventilation is used in a partial rebreathing circuit. The portable surgical unit is heated. The surgical team consists of a veterinary surgeon, a sterile assistant and a non-sterile anesthetist (@ Markus Horning, pursuant to NMFS permit no. 19309, AUP A/NW2016-1)

\section{The use of FITs should be justified for specific experimental designs in view of potential alter- natives and importance of data}

This justification needs to consider the mode, time frame and likelihood of data recovery, as well as the experimental design and sample size. Alternatives to consider may include: mark re-encounter studies based on temporary, permanent or natural markings; direct or remote observations of individual behavior and reproductive status; cross-sectional population counts; the use of externally attached telemetry devices; genetic studies; as well as other approaches. Valid justifications may include: essential data cannot be collected by any other means; or the predicted data recovery probability with sufficient statistical power, spatiotemporal resolution or sensitivity is too low for any alternative; or the alternatives are likely to result in greater impacts on individuals or greater disturbances on larger groups.

As an example, video observations combined with permanent markings have been successfully used for many vital rate studies in the Gulf of Alaska [66-68], but these approaches have not been technically viable for more remote locations in the Aleutian Islands. FITs such as LHX tags have the potential to provide data that cannot be collected by any other means in remote locations or at sea, such as exact dates, locations and causes of mortality-including predation events-or parturition events.

Justifications and alternatives should also be considered within the framework of the Three R's: Reduction, Refinement, Replacement [12, 69]. Reduction is often understood as the use of a smaller sample size; however, this can also be achieved by the more reliable collection of more or higher resolution data per subject [70]. Refinement refers to improvements in the way experiments are carried out that result in reductions of negative effects on animals or improved animal welfare. For example, implanted tags have the potential to reduce or eliminate dragrelated energetic costs associated with external tags, which may be considered a refinement [13, 29]. This potential refinement needs to be balanced against the impact of surgery. An important consideration is the anticipated duration of deployments in view of the cumulative effects on energy budgets in relation to progressively waning impacts of surgery. Incidental disturbance effects may be greater for markresight designs that may require substantially larger sample sizes and multiple physical site visits to determine re-encounter rates, as compared to knownfate sampling designs with spatially and temporally unrestricted telemetric re-encounter efforts, such as LHX tags. Known-fate sampling designs could be considered a reduction (in sample size) and a refinement (reduced disturbance). Replacement avoids the use of animals altogether. Recognized techniques for replacement include the use of already collected data. This could be facilitated through the telemetric collection of high-resolution, high-density data sets that may lead to enhanced opportunities to use computer models to simulate animal responses to situations or the environment. Thus, there is a direct relationship between the quality of data obtained in a study and the potential for future replacement.

Experimental designs should consider the a priori establishment of animal selection criteria. Some criteria may be linked to the experimental design such as sex, age or size and reproductive status. When the selection is not critical to the sampling design (i.e., differences in health status, size, age or other criteria are not the focus of the study), animals with 
lower risk of complications or those likely to have a lower population level impact, could be selected (e.g., larger or older animals, males). The inclusion or exclusion of animals as a function of their health status (e.g., body condition, injuries) is an important ethical consideration and can also increase data return probability and enhance data quality. However, use of such criteria may introduce biases in estimates (e.g., behavior or survival) that may or may not be correctable if the interest lies in understanding the entire population. Finally, it should be pointed out that cost savings alone are generally not considered an acceptable justification for the use of FITs [13].

2. Consider the most suitable locations for FITs and device fixation

In pinnipeds, FITs have been placed in subcutaneous locations $[41,50]$ and intraperitoneally $[43,53]$. The latter may be considered more invasive, and complications such as dehiscence and infections may lead to severe consequences, and even death. However, the subcutaneous blubber layer in aquatic mammals, and especially in phocids, is a highly vascularized and metabolically very active tissue [71]. This may result in a substantially greater likelihood of complications ranging from tissue reaction and inflammatory response to infection and extrusion (e.g., [41, $50,72]$ ). Devices placed within or underneath blubber are somewhat fixed by the requirement to create a space to accommodate the tag. Intraperitoneal devices however can be surgically fixed or remain free-floating in the abdominal cavity. Some researchers prefer to promote connective tissue growth and adhesion, in part to facilitate recovery of implanted devices [73], or to reduce likelihood of interfering with pregnancies and parturition. However, recovery of implanted devices has been feasible with freefloating implants in sea otters [40,47].

The potential for complications in free-floating devices should be considered: devices may become attached to the mesentery or omentum, may enter the omental bursa or may become lodged across the pelvic canal. Attachment may occur if the external surface of tags is coated with a material that allows or promotes adhesion, development of scar tissue and fibrous encapsulation. Entrapment may occur depending on the size, shape and mass of a device, in relation to the size of the bursa or the pelvic canal. Adhesion or entrapment may secondarily result in obstructed or torsed intestines, depending on the size, shape and mass of the device. Adhesion has been reported as responsible for some of the very few observed complications in intraperitoneal implants in beavers [74]. Other possible complications include obstruction of other tubular abdominal structures, such as the reproductive tract, pancreatic ducts or ureters. Device pressure can result in occlusion of vascular, nervous or lymphatic supply of abdominal structures and potential tissue necrosis.

Early studies using free-floating implants in mammals ranging in size from deer mice to brown bears have reported fewer mortalities than those using devices not designed to remain free-floating, and all concluded that the former was the preferred technique, generating fewer potentially critical complications (e.g., dehiscence, hemorrhaging, bacteremia and sepsis) than a subcutaneous application [72, 75-77]. In pinnipeds, studies have reported complications from subcutaneous devices [50-52]. However, no complications attributable to properly conducted intra-abdominal placement of sterilized FITs have been reported in literature, or encountered in our studies, suggesting this method as preferable to subcutaneous implantation [33, 37-40, 42, 45, 47, 49, 53].

3. Validate safe designs for FITs

We recommend that safe device designs be validated through the empirically confirmed absence of detectable effects beyond an initial, time-limited and expected response, for animals of comparable body shape, size, behavior, physiology and life history. There is a clear need to separately consider each species and life history stage rather than developing a single rule that fits all [8]. This applies to the selection of effect parameters monitored as well as the size and shape of FITs [9]. The expected responses to implant surgery that have to be considered at the very least include a foreign body response and a wound healing response. Monitoring parameters to consider include any that could be indicative of these two responses, examples include $\mathrm{CBC}$ including total white blood cell count and differentials, clinical chemistry values (e.g., total protein, globulins), acute-phase protein levels (e.g., fibrinogen, haptoglobin), as well as visual tracking of incision site healing. We further propose that device volume, mass, density or buoyancy and cross-sectional area all be considered and reported in validating safe designs. Traditionally, mass thresholds have been suggested but also criticized [8]. From the early days of implantable telemetry, recommendations were made for the mass of implanted telemetry devices not to exceed $2-5 \%$ of animal body mass [78-80], though these were not based on any quantitative assessment of effects of implants of various sizes on behavior and survival. Indeed, some references to largely anecdo- 
Table 1 Recommended descriptive device parameters, shown here for select tags used in recent marine mammal studies (see Table 2)

\begin{tabular}{|c|c|c|c|c|c|c|c|c|}
\hline Device & $\begin{array}{l}\text { Volume } \\
(\mathrm{ml})\end{array}$ & $\begin{array}{l}\text { Mass } \\
(\mathrm{g})\end{array}$ & $\begin{array}{l}\text { Area }^{a} \\
\left(\mathrm{~cm}^{2}\right)\end{array}$ & $\begin{array}{l}\text { Length }^{\mathbf{b}} \\
(\mathrm{mm})\end{array}$ & $\begin{array}{l}\text { Force }^{c} \text { (static, } \\
\text { submerged) } \\
\text { (N) }\end{array}$ & $\begin{array}{l}\text { Force }{ }^{\mathrm{d}} \text { (dynamic) } \\
\text { at } a=9.8 \mathrm{~ms}^{-2} \\
\text { (N) }\end{array}$ & $\begin{array}{l}\text { Pressure } \\
(\text { static) (N/ } \\
\left.\mathrm{mm}^{2}\right)\end{array}$ & $\begin{array}{l}\text { Pressure }^{f} \\
\text { (dynamic) }^{-2} \\
\text { at } a=9.8 \mathrm{~ms}^{-2} \\
\left(\mathrm{~N} / \mathrm{mm}^{2}\right)\end{array}$ \\
\hline $\mathrm{LHX} 1$ & 202 & 118 & 13.85 & 128 & -0.87 & 1.16 & 6.28 & 8.38 \\
\hline LHX2 & 79 & 54 & 8.55 & 97 & -0.26 & 0.53 & 3.04 & 6.20 \\
\hline VHF & 119 & 150 & 13.37 & 90 & 0.27 & 1.47 & 2.02 & 10.99 \\
\hline TDR & 17 & 35 & 2.3 & 69 & 0.18 & 0.34 & 7.83 & 14.78 \\
\hline Effect & $\begin{array}{l}\text { Body mass } \\
\text { set point }\end{array}$ & $\begin{array}{l}\text { Cost of } \\
\text { locomotion }\end{array}$ & Entrapment & Entrapment & $\begin{array}{l}\text { Cost of } \\
\text { locomotion }\end{array}$ & Cost of locomotion & Tissue effects & Tissue effects \\
\hline
\end{tabular}

\footnotetext{
a Smallest cross-sectional area

b Longest exterior dimension

${ }^{c}$ Force is calculated for subjects fully submerged in saltwater (density 1.025$)$ as $F(N)=[$ volume $(\mathrm{ml}) \times 1.025-$ mass $(\mathrm{g})] \times 9.8067\left(\mathrm{~ms} \mathrm{~s}^{-2}\right) / 1000 ;$ a negative value indicates the device is buoyant

$\mathrm{d}$ This corresponds to the inertial force resulting from the tag mass being exposed to an acceleration a and is calculated as $F(N)=m(\mathrm{~kg}) \times a\left(\mathrm{~ms} \mathrm{~s}^{-2}\right)$. For $a=g=9.8067 \mathrm{~ms}^{-2}$, the force is also equal to the tag weight in air at sea level

e,f This is a measure of the maximum pressure the tag exerts on surrounding tissue, and is calculated as force per unit area. Static pressure is exerted by the buoyancy in a non-moving submerged animal, and dynamic pressure is resulting from dynamic acceleration of the animal and varies with a. For $a=g$, this equals the pressure exerted by a tag in a non-moving, non-submerged animal
}

tal suggestions of size limits are based on completely arbitrary considerations such as the typical size or mass of mature eggs or fetus at the end of gestation (see [13]). Device mass is likely related to increased cost of locomotion, especially for birds [81, 82]. Paradoxically, some larger birds may be more affected by identical mass percentages than smaller birds ([81], and see [8]). Furthermore, device volume may be more closely related to altered body mass set points in some animals [83], and buoyancy may affect cost of locomotion more than mass [84, 85]. Several researchers have suggested that implant size indices based on the percentage device weight in water or volume to body mass ratios should be preferable for aquatic vertebrates [13, 17, 19, 31, 32]. Beaulieu et al. [32] specifically suggested using device volume per body mass $(\mathrm{ml} / \mathrm{kg})$ as a metric. They compared results from their own study to eight other studies on aquatic birds (mostly penguins). Their own ratios were approximately $4.5 \mathrm{ml} / \mathrm{kg}$. Two studies with comparably larger devices reported no effects on common eider $(6.5 \mathrm{ml} / \mathrm{kg})$ and harlequin ducks $(7.5 \mathrm{ml} / \mathrm{kg})$, though they cite the study by Culik and Wilson [28] as reporting effects at a mean ratio of $1.8 \mathrm{ml} / \mathrm{kg}$ (but note the above-mentioned electrodes, and anchored devices in the two bird studies). These divergent results further support the notion that for aquatic animals as well as other taxa, one size rule does not necessarily fit all.

Physical dimensions including length and the smallest cross-sectional area may relate to the likelihood of tag entrapment in the omental bursa, mesentery or the pelvic canal. Intestinal torsion secondary to omental entrapment or adhesion may be a function of the inertial or rotational forces an adhered device can generate for a given acceleration. Localized tissue effects may also be a function of the amount of pressure a tag can exert on surrounding tissue. Though a simplification, these effects can be standardized for comparative purposes via area-specific force (pressure), which may be approximated from device mass and shape.

Table 1 lists the parameters we recommend as comparative device descriptors, for a number of tags used in recent studies. All standardized, comparative static and dynamic forces and pressures can be calculated from volume, mass and area, and only the first four parameters need to be included in publications. It should be noted that dynamic values are of course dependent on animal movement. Values listed in Table 1 are based on a standard acceleration of $1 \mathrm{~g}\left(9.8 \mathrm{~ms}^{-2}\right)$ solely for comparative purposes. Quick acceleration or turns could result in much higher values.

Volume effects (on body mass set point) and mass effects (on cost of locomotion) are likely relative to host size, and thus species-specific demonstrated safe ratios expressed in proportion to body mass seem reasonable. Safe ratios for four aquatic mammals in which devices from Table 1 have been validated at least partially through the absence of negative effects, are shown in Table 2. 
Table 2 Tag volumes and mass relative to body mass from select recent studies in four aquatic mammal species using intra-abdominal dual FITs

\begin{tabular}{lllllll}
\hline Species & Tags & $\mathbf{n}$ & $\mathbf{m l} \mathbf{k g}$ & \% Body mass & Effect testing & References \\
\hline California sea lion & LHX & 2 & $2.2(3.1)$ & $0.13(0.18)$ & $1,2,5,6$ & {$[43]$} \\
California sea lion & LHX + LHX & 2 & $2.4(2.9)$ & $0.14(0.17)$ & $1,2,5,6$ & {$[43]$} \\
Steller sea lion & LHX & 2 & $1.8(1.9)$ & $0.10(0.11)$ & $1,2,3,4,5,6,7,8$ & {$[43,46,49,57,60,63,65]$} \\
Steller sea lion & LHX + LHX & 34 & $3.1(5.5)$ & $0.18(0.32)$ & $1,2,3,4,5,6,7,8,10$ & {$[43,46,49,57,59-65]$} \\
Steller sea lion & LHX + LHX2 & 9 & $2.8(3.8)$ & $0.17(0.23)$ & $1,2,3,4,5,6,7,8,9,10$ & {$[49,59-65]$} \\
Harbor seal (pup) & LHX2 & 3 & $6.0(6.3)$ & $0.41(0.43)$ & $1,2,3,4,5,6,7,8,10$ & {$[53]$} \\
Harbor seal & LHX2 + LHX2 & 10 & $2.5(3.6)$ & $0.17(0.24)$ & $6,7,8,9,10$ & {$[$ Horning et al. unpubl. data] } \\
Sea otter & VHF + TDR & 31 & $5.0(7.1)$ & $0.68(0.97)$ & n/a & {$[40,47]$} \\
\hline
\end{tabular}

For applications with multiple internal tags, volumes and masses are summed. $n$ refers to sample sizes in referenced studies. Mean values are listed with maximum ratios in parentheses, and sample size is indicated. Effect testing conducted in these studies—some continuing-is indicated with references to publications

Effect testing 1. captive postop monitoring $\geq 6$ weeks, mass (gain), appetence, 2 . postoperative transmitted temperatures, 3. CBC and differential, 4 . acute and chronic inflammatory responses measures, 5. captive behavior, 6. postrelease movement, 7. postrelease behavior, 8. postrelease survival, 9. postrelease reproduction, 10. in progress/continuing

The effects of forces that tags can exert to raise the cost of locomotion and that may contribute to intestinal torsion, and also the effects of pressure on surrounding tissues (see Table 1) are directly driven by physical properties of the tag and are independent from the size of their host. The above considerations also suggest that smaller is not necessarily always better, and that safe volume and mass ratios should not be interpreted as thresholds. Values below tested ratios may only be considered safe in conjunction with an evaluation of static and dynamic forces and pressures. Published ratios and force values should be useful in comparing and optimizing tag designs, and informing experimental designs, but do not eliminate the need to conduct impact assessments. Priority should be given to validating and reporting safe designs.

4. Use devices with an outer material tested for biological reactivity or conduct biocompatibility testing with actual FITs

As a general rule, the materials encasing or leaching out of an FIT have the potential to evoke a foreign body response [86]. Foreign body reactions to implanted objects vary in severity and may lead to phagocytic attacks, fibrous encapsulations and chronic inflammation, as well as many other acute, medium- and long-term effects [86]. Very few studies have investigated long-term histochemical effects of FITs on wild animals. A number of studies have identified persistent pathological reactions attributable to FITs, ranging from organ-invading granulation in wild carp [87] to peritoneal sarcomatosis in laboratory rats [88]. Surface coating FITs with biocompatible materials is one way to minimize inflammatory response and reduce macrophage adhesion and foreign body giant cell growth, which may also reduce delays in wound healing. The type of material used (polymeric, ceramic, metallic) is not connected to biocompatibility, but passivating the material surface to minimize non-specific protein interaction may be key [89].

We strongly recommend to only use devices with outer materials that have been tested and approved either under the United States Pharmacopeia (USP) Class 6 standard for biological reactivity or preferentially the newer ISO-10993 standard for biocompatibility [90]. Alternatively, investigators could consider conducting assessments similar to those allowed under the ISO standard. The USP standard investigates biological reactivity of elastomers, plastics and polymeric materials in vitro and in vivo. Under Class 6 , these standardized tests are conducted on materials in non-polymerized and cured states: acute system toxicity test, intracutaneous test and implantation test. Certified cured compounds must furthermore meet strict requirements on leachates. The duration of implantation test is however very limited to five days. Certification of coatings and materials to the USP standard does not prove favorable biocompatibility of devices. However, the use of USPcertified materials is more likely to result in favorable biocompatibility results. ISO-10993 addresses biocompatibility and moves well beyond the USP certification by considering cytotoxicity, sensitization, acute systemic toxicity, chronic toxicity, subchronic toxicity, genotoxicity, hemocompatibility, thrombogenicity, pyrogenicity, carcinogenicity as well as reproductive and developmental toxicity and biodegradation. Using devices coated with an ISO10993-certified material is one option for investiga- 
tors. However, under ISO-10993-6, an in vivo study of the FIT may replace some of the above-listed in vitro tests of constituent materials if the study was designed for this purpose, with appropriate assessment endpoints, and all recommended scientific principles were applied. Appropriate assessments may include laparoscopic or histological screening for inflammatory response. Recommended durations for in vivo implant testing range from 12 to 78 weeks. Durations for testing constituent components and materials can be shorter, from 8 to 12 weeks [90]. In addition to device descriptors listed in Table 1, all studies should always include details on the type of material coating all FITs used, and how biocompatibility was determined.

5. Use devices that meet pressure ratings with a $3 \mathrm{x}$ margin of safety for the species of interest

Damage to an FIT deployed in a diving animal from excessive pressurization is likely to have catastrophic and potentially fatal consequences for the host, especially for FITs containing hollow spaces or lithium batteries. Yet, no safety ratings exist for such applications. There are two aspects to consider: uncertainty about the likely maximum depth exposure and engineering design rules for fatigue and manufacturing tolerances. We propose the following safety factors. With standard deviations for the maximum dive depths reported for most species averaging about 25\% [91], the mean of reported maxima plus $4 \times$ the standard deviation is likely to contain $99.999 \%$ of cases, suggesting a safety factor of $2 \times$ mean of reported maximum depths. Deep ocean high-pressure manufacturing industry uses a design rule safety factor of $1.5 \times[92,93]$. Together, these yield a $3 \times$ safety factor for FIT pressure ratings. Data from adults should be used for FITs likely to remain implanted into adulthood. For sexually dimorphic species, data from the targeted sex should be used. To give an example, if the mean of all maximum dive depths reported for adults of a species is $350 \mathrm{~m} \pm 25 \% \mathrm{SD}$, then a rating of $700 \mathrm{~m}$ will likely not be exceeded by more than 1 in 1000 individuals. Applying the engineering factor of $1.5 \times$ will then lead to a pressure rating design requirement of $1050 \mathrm{~m}$ for FITs used in this project.

6. Use approved designs for lithium primary cells in FITS

Most FITs use lithium primary batteries as a result of their high energy density. Such cells are safe to use for biomedical implants and FITs, providing standard safety measures are implemented [94]. These include using only cells with a lithium metal content less than $1 \mathrm{~g}$ per cell and with protective measures to limit current and temperature (such as thermal fuses). Multi-cell systems need to be protected against imbalanced discharge of cells. Complete discharge of lithium primary cells can be problematic, and needs to be managed by device electronics, or tested.

\section{Properly sterilize all FITs}

Like any vertebrate, pinnipeds are susceptible to infections from contaminated FITs, and full sterilization is therefore absolutely essential. Sterilization requires the complete removal or destruction of all pathogens including microorganisms, spores and virus from the FIT and is distinct from disinfection. Dipping FITs in disinfectant solutions, such as any alcohol or chlorhexidine, does not result in sterilization and is therefore not acceptable for any FIT applications. There are liquid sterilants such as glutaraldehyde that can be used only if the required concentrations, temperatures and immersion durations (often on the order of hours) are strictly maintained. Gas sterilization by ethylene oxide or hydrogen peroxide plasma is effective and has the advantage of allowing prepackaging of FITs for easy transport and field use after sterilization. All methods may have advantages and disadvantages, such as toxicity of agents, the requirement of specialized equipment, presence of residue and chemical or thermodynamic interactions with FITs. It is essential that sterilization is fully maintained until and during FIT insertion, and that any sterilizing agents are properly outgassed and any residue rinsed off via sterile saline prior to insertion. Any FIT with possibly compromised sterility should not be used. For a review, see [10, 13, 95].

8. Use accepted, standardized aseptic surgery procedures

For the same reasons described under recommendation 7, following standard aseptic procedures is essential. This includes use of a clean environment and sterile equipment including drapes, surgical garbs, gloves and instruments. The skin incision site should be properly prepared using aseptic technique and isolated by sterile drapes. See [10, 13, 29].

\section{Use appropriate anesthesia and analgesia}

The surgical implantation of an FIT without a surgical plane of anesthesia is an inhumane act and should not be performed. Subjects should be appropriately monitored during procedures and recovery. Modern, multi-modal peri- and postoperative analgesia should always be used to mitigate pain [13, 95-97]. Proper pain management will likely prevent delayed recovery and improve the outcomes of projects using FITs. 
10. Surgeries, anesthesia and postoperative monitoring should be conducted or directly supervised by qualified and appropriately trained personnel

Personnel should also be knowledgeable and experienced in medical and surgical care of subject species including emergency treatment.

11. Consider the advantages and disadvantages of prophylactic treatment with antibiotics, within regulatory constraints

The prophylactic application of antibiotics has been proposed and practiced but is not without controversy, in part as a result of increased incidence of pathogens resistant to antibiotics (e.g., [98, 99]). A determination for use of prophylactic antibiotics should be made based on a number of factors including the nature of the procedure, technique used, facilities available, potential surgical complications, postsurgical release site and anticipated behavior of the animal. Considerations should include use of antimicrobial suture material. Because pinnipeds may be legally harvested in some localities, regulatory constraints related to food animals may also apply. See [13, 29, 95].

12. Plan, conduct and report on assessment of short-, medium-and long-term FIT effects

As researchers using FITs, we have to consider any possible effects of devices or associated procedures on the data to be collected and on the study subjects [8-10, 13, 29, 95]. The former is an absolutely essential component of the scientific process. The latter derives from the application of accepted principles of ethical treatment of research subjects. Ethical considerations also dictate that the determination of FIT impacts be extended at least through the likely period of device retention and not just through the period of collection of data from FITs. Some projects have successfully carried out the deployment and subsequent recovery of FITs in wild aquatic mammals [40, 47, 48]. However, the majority of FITs deployed on wild animals will never be recovered [49-52] and will therefore be carried by the host animal for the remainder of their lives. As a result, we should consider three broad time periods when planning and conducting studies of FIT effects:

\section{a) Short-term effects ranging from hours to days}

Detecting and understanding short-term effects may be critical to determining how quickly after a procedure animals may be safely released and to improving procedures and mitigating effects. Examples of possible short-term effects may include discomfort and pain, as well as reduced appetence, mobility or vigilance. Assessments may include physiology (temperature, stress hormones, blood metabolites), behavior and movement (posture, resting), and changes in food intake, and could take advantage of data from the FITs (e.g., body core temperatures, data from accelerometers) (e.g., [53, 59-62]).

b) Medium-term effects ranging from days to months

These effects are critical in determining possible impacts on data. Until demonstrated otherwise, it is necessary to assume that for a given period after surgery and until all healing processes are completed, implanted subjects may experience impaired movement, performance or foraging ability.

Two recent FIT studies revealed measurable physiological responses linked to inflammatory processes that persisted through at least five weeks after surgery $[53,57]$. Such assessments may initially require captive work under controlled conditions for the purpose of developing a study inclusion criterion (see recommendation \#13). Alternatively, a controlled effort in captivity could identify suitable proxies to derive a study inclusion criterion after release, especially given the desirability of minimizing captivity (see recommendation \#14), and since captivity may also lead to effects. Assessments for medium-term effects may include monitoring of inflammatory response, analysis of activity patterns and effects on growth, foraging behavior, reproductive behavior, movement and migration. Data from internal or external tags may prove useful, providing the devices will not affect the assessment (e.g., [53, 57, 60, 63]).

c) Long-term effects ranging from months to years and through the likely period of FIT retention

Understanding and quantifying long-term effects is crucial to any vital rate studies. Furthermore, some effects may have low-level accumulating impacts that may become more detectable when integrated over longer periods of time $[11,100]$. While short- and medium-term effects may be studied at the level of proximate mechanisms, long-term effects can more readily be assessed via ultimate impacts on growth, migration, reproduction and survival (e.g., [65]).

It is inappropriate to assume that FITs will not affect data or subjects simply based on size or mass percentages (see recommendation \#3) or 
based on demonstrated absence of effects in other species carrying similar devices. Evidence supports that effect magnitudes are specific to species, devices, animal state and circumstances [8]. Transferability of such findings across species and devices is therefore limited, and it is prudent to always carry out and report control studies $[8,9]$.

Implanted tags may also passively or actively increase the detectability of hosts by predators. Some tags may be echogenic and may produce acoustic or electromagnetic signatures. Acoustic emissions could also be perceived by hosts and may alter their behaviors. Where possible, researchers should consider using FITs and external tags to provide assessment data. Recent developments enable life-long FITs to provide survival and reproductive data, and developments to enable electronic mark-resight designs using FITs are underway (e.g., [6]). If FITs are used to collect vital rate or assessment data, then the failure rate of tags or data recovery probability needs to be accurately quantified and corrected for $[46,49]$. Even outside of vital rate studies, data on tag failure rates will be useful in planning future telemetry studies. The simultaneous deployment of multiple internal or external tags may be a powerful tool in support of long-term vital rate and FIT assessment studies. However, with increasing manipulations and tag burdens proper assessments on combined loads will become even more critical.

13. Derive and apply a specific study inclusion criterion

Many FIT studies referenced here were designed to collect primary data within days of surgery, when the presence of effects from surgery and devices has to be assumed. Very few of these studies specifically derived and reported a study inclusion criterion (see also [5, 9]). An arbitrary cutoff not backed by applicable data does not support the absence of FIT effects in the data set and is no better than not using a criterion. Without a specific, quantitative criterion backed by demonstrated absence of effects or a valid argument about transferability of inclusion criteria, reported findings lack scientific validity.

14. Minimize manipulations and temporary captivity

The report by the Joint Working Group on Refinement [13] recognizes that wild animals are liable to find capture and handling extremely stressful and that this represents an experimental harm.' The working group report specifically recommends to
'Carefully consider the duration of postsurgery captivity'. In connection with FIT implantation surgery, project planners should therefore weigh any potential benefits of controlled access and monitoring and potential disadvantages of stress and delayed return to the natural environment when under temporary captivity. Amount and lengths of manipulations as well as duration of temporary captivity for wild animals before and after surgery should be limited as much as possible $[8,101,102]$. However, captive monitoring is an extremely valuable experimental tool and can lead to refinements in considering postoperative recovery and monitoring periods through detailed studies of discomfort and pain, wound healing, observations of postoperative complications or confirmation of their absence and observations of postoperative behaviors.

\section{Report all findings in accessible, peer-reviewed} literature

It is imperative that all findings, including negative effects, are reported in readily accessible peerreviewed literature. This includes details on safe FIT designs, surface materials and biocompatibility, study inclusion criteria, results from all effect assessments, as well as tag failure rates and data recovery probabilities. The latter are essential for sample size estimation and the development of future projects.

\section{Conclusions}

We present 15 specific best practice recommendations for the application of fully implanted telemetry devices in pinnipeds. These recommendations should be considered by researchers preparing projects and by regulatory bodies authorizing projects. These initial recommendations may be refined or adjusted through new studies, within the guiding principles of the Three R's [69]. Deviations or exceptions should be considered only when convincingly justified. While we developed these recommendations specifically for pinnipeds, some may be applicable to other groups of aquatic animals, such as sea otters or aquatic birds, or other applications, such as partially implanted (transdermal) tags, or even external tags. For all users and regulators of FITs, it will be important to avoid creating a 'catch 22' situation, where studies are not allowed to proceed or be published until the absence of negative effects has been demonstrated. Such determinations cannot be carried out without risking these effects and will require sample sizes that cannot usually be achieved through single studies. A prudent approach may therefore gradually build on initial control and validation studies, while providing plans to carry out effect assessments at all appropriate temporal scales. 


\section{Abbreviations}

CBC: complete blood count; FIT: fully implanted tag; LHX: life history transmitter; VHF: very high frequency.

\section{Authors' contributions}

MHo drafted manuscript and designed referenced FITs, MHa and PAT developed referenced implant surgery protocol, $\mathrm{MHO}$, JEM and $\mathrm{MHa}$ designed and conducted referenced FIT studies, MHa, PAT, CEG, RKB, KW and SJ conducted implant surgeries, MHo, JEM, KAW, CRS, JPS and PLB designed or conducted referenced assessment studies. All authors participated in referenced implant studies, postoperative monitoring or assessment studies referenced here. All authors read and approved final manuscript.

\section{Author details \\ 1 Alaska SeaLife Center, 301 Railway Avenue, Seward, AK 99664-1329, USA. \\ ${ }^{2}$ Marine Mammal Institute, Oregon State University, 2030 SE Marine Sci- ence Drive, Newport, OR 97365, USA. ${ }^{3}$ Vancouver Aquarium, 845 Avison Way, Vancouver, BC V6G 3E2, Canada. ${ }^{4}$ Bridge Veterinary Services LLC, 9162 Glacierwood Drive, Juneau, AK 99801, USA. ${ }^{5}$ The Marine Mammal Center, 2000 Bunker Rd, Sausalito, CA 95965, USA. ${ }^{6}$ Department of Biosciences, Durham University, South Road, Durham DH1 3LE, UK. ${ }^{7}$ University of British Columbia, 2357 Main Mall, Suite 180, Vancouver, BC V6T 1Z4, Canada. ${ }^{8}$ Marine Mammal Laboratory, NOAA Alaska Fisheries Science Center, 7600 Sand Point Way NE, Seattle, WA 98115, USA.}

\section{Competing interests}

$\mathrm{MHO}$ is the co-developer of LHX tags in collaboration with Wildlife Computers, Inc. (Redmond, WA). Development of LHX tags was funded by the National Science Foundation (US), and a stated goal of the development grant is the future commercial availability of LHX tags to the general user community.

\section{Funding}

The lead author was supported by the Alaska SeaLife Center and by the Marine Mammal Endowment of Oregon State University.

\section{Publisher's Note}

Springer Nature remains neutral with regard to jurisdictional claims in published maps and institutional affiliations.

Received: 31 January 2017 Accepted: 26 May 2017

Published online: 08 June 2017

\section{References}

1. Cooke SJ, Hinch SG, Wikelski M, Andrews RD, Kuchel LJ, Wolcott TG, Butler PJ. Biotelemetry: a mechanistic approach to ecology. Trends Ecol Evol. 2004;19:334-43.

2. Kays R, Crofoot MC, JetzW, Wikelski M. Terrestrial animal tracking as an eye on life and planet. Science. 2015;348:aaa2478.

3. Hooker SK, Biuw M, McConnell BJ, Miller PJO, Sparling CE. Bio-logging science: logging and relaying physical and biological data using animal-attached tags. Deep Sea Res II. 2007;54:177-82.

4. Hazen EL, Maxwell SM, Bailey H, Bograd SJ, Hamann M, Gaspar P, Godley BJ, Shillinger GL. Ontogeny in marine tagging and tracking science: technologies and data gaps. Mar Ecol Prog Ser. 2012;457:221-40.

5. Mclntyre T. Trends in tagging of marine mammals: a review of marine mammal biologging studies. Afr J Mar Sci. 2014;36(4):409-22.

6. Hussey NE, Kessel ST, Aarestrup K, Cooke SJ, Cowley PD, Fisk AT, Harcourt RG, Holland KN, Iverson SJ, Kocik JF, Mills Flemming JE, Whoriskey FG. Aquatic animal telemetry: a panoramic window into the underwater world. Science. 2015;348(6240):1255642.

7. Walker BG, Boveng PL. Effects of time-depth recorders on maternal foraging and attendance behavior of Antarctic fur seals (Arctocephalus gazella). Can J Zool. 1995;73:1538-44.

8. Casper RM. Guidelines for the instrumentation of wild birds and mammals. Anim Behav. 2009;78:1477-83.
9. Walker KA, Trites AW, Haulena M, Weary DM. A review of the effects of different marking and tagging techniques on marine mammals. Wildl Res. 2012:39:15-30.

10. Mulcahy DM. Legal, ethical, and procedural bases for the use of aseptic techniques to implant electronic devices. J Fish Wildl Manag. 2013:4:211-9

11. Maresh JL, Adachi T, Takahashi A, Naito Y, Crocker DE, Horning M, Williams TM, Costa DP. Summing the strokes: energy economy in northern elephant seals during large-scale foraging migrations. Mov Ecol. 2015;3:22.

12. Einstein $R$, Rowan $C$, Billing $R$, Lavidis $N$. The use of telemetry to refine experimental technique. In: Balls M, van Zeller A-M, Halder ME, editors. Progress in reduction, refinement and replacement of animal experimentation. Amsterdam: Elsevier; 2000. p. 1187-97.

13. Hawkins $P$, (editor). Refinements in telemetry procedures. Seventh Report of the BVAAWF/FRAME/RSPCA/UFAW Joint Working Group on Refinement, Part A, vol 37, pp 261-299. Laboratory Animals; 2003

14. National Research Council 2011. Guide for the care and use of laboratory animals. 8th ed. Institute for Laboratory Animal Research, p. 246. Washington, DC: National Academies Press; 2011.

15. Sikes RS, Paul E, Beaupre SJ. Taxon-specific guidelines versus US public health service policy. Bioscience. 2012;62:830-4.

16. AFS. Guidelines for the use of fishes in research. Bethesda: American Fisheries Society; 2014. p. 57.

17. Brown RS, Cooke SJ, Anderson WG, McKinley RS. Evidence to challenge the "2\% rule" for biotelemetry. N Am J Fish Manag. 1999;19:867-71.

18. Bridger CJ, Booth RK. The effects of biotelemetry transmitter presence and attachment procedures on fish physiology and behavior. Rev Fish Sci. 2003:11:13-34.

19. Brown RS, Harnish RA, Carter KM, Boyd JW, Deters KA. An evaluation of the maximum tag burden for implantation of acoustic transmitters in juvenile Chinook salmon. N Am J Fish Manag. 2010;30:499-505.

20. McMichael GA, Eppard MB, Carlson TJ, Carter JA, Ebberts BD, Brown RS, Weiland M, Ploskey GR, Harnish RA, Deng ZD. The juvenile salmon acoustic telemetry system: a new tool. Fisheries. 2011;35:9-22.

21. Panther JL, Brown RS, Gaulke GL, Deters KA, Woodley CM, Eppar MB. Influence of incision location on transmitter loss, healing, survival, growth, and suture retention of juvenile Chinook salmon. Trans Am Fish Soc. 2011;140:1492-503.

22. Childs AR, NaesjeTF, Cowley PD. Long-term effects of different-sized surgically implanted acoustic transmitters on the sciaenid Argyrosmus japonicus: breaking the 2\% tag-to-body mass rule. Mar Freshw Res. 2011;62:432-8.

23. ASIH. Guidelines for use of live amphibians and reptiles in field and laboratory research. 2 nd ed. Lawrence: American Society of Ichthyologists and Herpetologists; 2004. p. 43

24. Fair J, Paul $E$, Jones J, editors. Guidelines to the use of wild birds in research. Washington, D.C.: Ornithological Council; 2010. p. 215.

25. Sikes RS, et al. Guidelines of the American Society of mammalogists for the use of wild mammals in research. J Mamm. 2016:92:235-53.

26. Gales NJ, Bowen WD, Johnston DW, Kovacs KM, Littnan CL, Perrin WF, Reynolds JE III, Thompson PM. Guidelines for the treatment of marine mammals in field research. Mar Mamm Sci. 2009;25:725-36.

27. Croll DA, Gaston AJ, Burger AE, Konnoff D. Foraging behaviour and physiological adaptation for diving in thick-billed murres. Ecology. 1992;73:344-56.

28. Culik B, Wilson RP. Swimming energetics and performance of instrumented Adelie penguins (Pygoscelis adeliae). J Exp Biol. 1991;158:355-68.

29. Hawkins P. Bio-logging and animal welfare: practical refinements. Mem Natl Inst Polar Res. 2004;Spec Issue 58:58-68.

30. Barron DG, Brawn JD, Weatherhead PJ. Meta-analysis of transmitter effects on avian behaviour and ecology. Methods Ecol Evol. 2010;1:180-7

31. White CR, Cassey P, Schimpf NG, Halsey LG, Green JA, Portugal SJ. Implantation reduces the negative effects of bio-logging devices on birds. J Exp Biol. 2013;216:537-42.

32. Beaulieu M, Ropert-Coudert Y, Le Maho Y, Ancel A. Is abdominal implantation of devices a good alternative to external attachment? A comparative study in Adelie penguins. J Ornithol. 2010;151:579-86. 
33. Reid DG, Melquist WE, Woolington JD, Noll JM. Reproductive effects of intraperitoneal transmitter implants in river otters. J Wildl Manag. 1986:50:92-4.

34. Lacki MJ, Smith PN, Peneston WT, Vogt DF. Use of methoxyflurane to surgically implant transmitters in muskrats. J Wildl Manag. 1989;53:331-3.

35. Wheatley M. A new surgical technique for implanting radio transmitters in beavers, Castor canadensis. Can Field Nat. 1997;111:601-6.

36. Johnson SA, Berkley KA. Restoring river otters in Indiana. Wildl Soc Bull. 1999;27:419-27.

37. Monnett CC, Rotterman LM. Survival rates of sea otter pups in Alaska and California. Mar Mamm Sci. 2000;16:794-810.

38. Hernandez-Divers SM, Kollias GV, Abou-Madi N, Hartup BK. Surgical technique for intra-abdominal radiotransmitter placement in North American river Otters (Lontra canadensis). J Zoo Wildl Manag. 2001;32:202-5.

39. Fernandez-Moran J, Saavedra D, Manteca-Vilanova X. Reintroduction of the Eurasian otter (Lutra lutra) in Northeastern Spain: trapping, handling, and medical management. J Zoo Wild I Med. 2002;33:222-7.

40. Bodkin JL, Esslinger GG, Monson DH. Foraging depths of sea otters and implications to coastal communities. Mar Mamm Sci. 2004:20:305-21.

41. Lander ME, Haulena M, Gulland FMD, Harvey JT. Implantation of subcutaneous radio transmitters in the harbor seal (Phoca vitulina). Mar Mamm Sci. 2005;2005(21):154-61.

42. Nolfo LE, Hammond EE. A novel method for capturing and implanting radiotransmitters in nutria. Wildl Soc Bull. 2006;34:104-10.

43. Horning M, Haulena M, Tuomi P, Mellish J. Intraperitoneal implantation of life-long telemetry transmitters in otariids. BMC Vet Res. 2008:4:51.

44. Green JA, Haulena M, Boyd IL, Calkins D, Gulland F, Woakes AJ, Butler PJ. Trial implantation of heart rate data loggers in pinnipeds. J Wildl Manag. 2009;2009(73):115-21.

45. Bohrman JA, Stevens SS, Serfass TL. Long-term survival and reproduction in a North-American river Otter (Lontra canadensis) with an intraperitoneal radio-transmitter. Can Field Nat. 2011:125:252-4.

46. Horning M, Mellish JE. Predation on an upper trophic marine predator, the Steller sea lion: evaluating high juvenile mortality in a density dependent conceptual framework. PLoS ONE. 2012;7(1):e30173.

47. Bodkin JL, Ballachey BE, Coletti HA, Esslinger GG, Kloecker KA, Rice SD, Reed JA, Monson DH. Long-term effects of the 'Exxon Valdez' oil spill: sea otter foraging in the intertidal as a pathway of exposure to lingering oil. Mar Ecol Prog Ser. 2012;447:273-87.

48. Esslinger GG, Bodkin JL, Breton AR, Burns JM, Monson DH. Temporal patterns in the foraging behavior of sea otters in Alaska. J Wildl Manag. 2014;78:689-700.

49. Horning M, Mellish JE. In cold blood: evidence of Pacific sleeper shark (Somniosus pacificus) predation on Steller sea lions (Eumetopias jubatus) in the eastern Gulf of Alaska. Fish Bull. 2014;112:297-310.

50. Blundell GM, Hoover-Miller AA, Schmale CA, Berngartt RK, Karpovich SA. Efficacy of subcutaneous VHF implants and remote telemetry monitoring to assess survival rates in harbor seals. J Mamm. 2014:95:707-21.

51. Manugian S, Van Bonn W, Harvey JT. Modified technique for the subcutaneous implantation of radio transmitters in harbour seals (Phoca vitulina richardii) under field conditions. Vet Rec Case Rep. 2015;2015(3):e000154

52. Manugian S, Greig D, Lee D, Becker BH, Allen S, Lowry MS, Harvey TJ. Survival probabilities and movements of harbor seals in central California. Mar Mam Sci. 2017;33:154-71.

53. Horning M, Haulena M, Rosenberg JF, Nordstrom C. Intraperitoneal implantation of life-long telemetry transmitters in three rehabilitated harbor seal pups. BMC Vet Res. 2017:13:139

54. Horning M, Hill R. Designing an archival satellite transmitter for life-long deployments on oceanic vertebrates: the life history transmitter. IEEE J Ocean Eng. 2005;30:807-17.

55. Horning M, Mellish JE. Spatially explicit detection of predation on individual pinnipeds from implanted post-mortem satellite data transmitters. Endanger Species Res. 2009;10:135-43.

56. Mellish J, Calkins D, Christen D, Horning M, Rea L, Atkinson S. Temporary captivity as a research tool: comprehensive study of wild pinnipeds under controlled conditions. Aquat Mamm. 2006;32:58-65.

57. Mellish J, Thomton J, Horning M. Physiological and behavioral response to intra-abdominal transmitter implantation in Steller sea lions. J Exp Mar Biol Ecol. 2007;351:283-93.
58. Shuert C, Mellish J, Horning M. Physiological predictors of long-term survival in juvenile Steller sea lions (Eumetopias jubatus). Conserv Physiol. 2015. doi:10.1093/conphys/cov043.

59. Skinner JP, Tuomi PA, Mellish JE. The influence of time in captivity, food intake and acute trauma on blood analytes of juvenile Steller sea lions, Eumetopias jubatus. Conserv Physiol. 2015;3:cov008.

60. Petrauskas L, Atkinson S, Gulland F, Mellish J, Horning M. Monitoring glucocorticoid response to rehabilitation and research procedures in California and Steller sea lions. J Exp Zool. 2008;309A:73-82.

61. Walker K, Horning M, Mellish J, Weary D. Behavioral responses of juvenile Steller sea lions to abdominal surgery: an assessment of postoperative pain. Appl Anim Behav Sci. 2009;120:201-7.

62. Walker K, Horning M, Mellish J, Weary D. The effects of two analgesic regimes on behaviour after abdominal surgery in Steller sea lions. Vet J. 2011;190:160-4.

63. Thomton J, Mellish J, Horning M. Effects of temporary captivity on diving and ranging behavior of juvenile Steller sea lions, Eumetopias jubatus. Endanger Species Res. 2008;4:195-203.

64. IASP (International Association for the Study of Pain). IASP Taxonomy, retrieved from: http://www.iasp-pain.org/Education/Content.aspx?ltem Number $=1698 \&$ navltemNumber $=576$ on January 17, 2017.

65. Shuert C, Horning M, Mellish J. The effect of novel research activities on long-term survival of temporarily captive Steller Sea Lions (Eumetopias jubatus). PLoS ONE. 2015;10:e0141948.

66. Maniscalco JM, Springer AM, Parker P. Natality rates of endangered Steller sea lions in Kenai Fjords, Alaska and perceptions of population status in the Gulf of Alaska. PLoS ONE. 2010;5(4):e10076.

67. Maniscalco JM. The effects of birth weight and maternal care on survival of juvenile Steller Sea lion (Eumetopias jubatus). PLoS ONE. 2014;9(5):96328.

68. Maniscalco JM, Springer AM, Adkinson MD, Parker P. Population trend and elasticities of vital rates for steller sea lions (Eumetopias jubatus) in the Eastern Gulf of Alaska: a new life-history table analysis. PLoS ONE. 2015;10(10):e0140982.

69. Russell WMS, Burch RL. The principles of humane experimental technique. London: Methuen; 1959.

70. Festing $M$. The Design of animal experiments: reducing the number of animals in research through better experimental design, Laboratory Animal Handbooks. London: SAGE Publications Ltd.; 2016. p. 144.

71. Pabst A, Rommel SA, McLellan WA. The functional morphology of marine mammals, chapter 2. In: Reynolds JE, Rommel SA, editors. Biology of marine mammals. Washington, D.C.: Smithsonian Institution Press; 1999. P. 578.

72. Garshelis DL, Siniff DB. Evaluation of radio-transmitter attachment for sea otters. Wildl Soc Bull. 1983;11:378-83.

73. Fuglei E, Mercer JB, Arnemo JM. Surgical implantation of radio transmitters in arctic foxes (Alopex lagopus) on Svalbard, Norway. J Zoo Wild Med. 2002:33:342-9.

74. Guynn DC, Davis JR, Von Recum AF. Pathological potential of intraperitoneal transmitter implants in beavers. J Wildl Manag. 1987:51:605-6.

75. Neely RD, Campbell RW. A system for gathering small mammal mortality data. US For Serv Res Pap. 1973:NE-280:1-6.

76. Philo ML, Follman EH. Field surgical techniques for implanting temperature sensitive radio transmitters in grizzly bears. J Wildl Manag. 1981;45:772-5.

77. Agren EO, Nordenberg L, Mörner T. Surgical implantation of radiotelemetry transmitters in European badgers (Meles meles). J Zoo Wildl Med. 2000;31:52-5.

78. Brander RB, Cochran WW. Radio location telemetry. In: Giles Jr. RH, editor. Wildlife management techniques. Washington, D.C.: The Wildlife Society; 1969. p. 95-103.

79. MacDonald DW, Amlaner CJ. A practical guide to radio tracking. In: Amlaner CJ, MacDonald DW, editors. A handbook on biotelemetry and radio tracking. Oxford: Pergamon Press; 1980. p. 143-59.

80. Winter JD. Underwater biotelemetry. In: Nielsen LA, Johnsen JD, editors. Fisheries techniques. Bethesda: American Fisheries Society; 1983. p. 371-95.

81. Caccamise DF, Hedin RS. An aerodynamic basis for selecting transmitter load in birds. Wilson Bull. 1985:97:306-18. 
82. Ropert-Coudert Y, Bost C-A, Handrich Y, Bevan R, Butler PJ, Woakes AJ, Le Maho Y. Impact of externally-attached loggers on the diving behaviour of the king penguin. Physiol Biochem Zool. 2000;74:438-44.

83. Bradley P. The ponderostat and a physiological model of obesity. Am J Clin Nutr. 1978;31:1975-7.

84. Webb PM, Crocker DE, Blackwell SB, Costa DP, LeBoeuf LE. Effects of buoyancy on the diving behavior of northern elephant seals. J Exp Biol. 1998;201:2349-58.

85. Biuw M, McConnell B, Bradshaw CJA, Burton H, Fedak M. Blubber and buoyancy: monitoring the body condition of free-ranging seals using simple dive characteristics. J Exp Biol. 2003;206:3405-23.

86. Bryers JD, Giachelli CM, Ratner BD. Engineering biomaterials to integrate and heal: the biocompatibility paradigm shifts. Biotechnol Bioeng. 2012;109:1898-911.

87. Bauer C, Loupal G. Common carp tissue reactions to surgically implanted radio tags with external antennas. J Fish Biol. 2007;70:292-7.

88. Shoieb A, Allavena R, Swallow J, Debrue M. Peritoneal sarcomatosis associated with telemetry implants in sprague dawley CD rats: a review of eight cases. Toxicol Pathol. 2012;40:113-21.

89. Chen H, Yuan L, Song W, Zu W, Li D. Biocompatible polymer materials: Role of protein-surface interactions. Prog Polym Sci. 2008;33:1059-87.

90. ISO 10993. Biological evaluation of medical devices. Geneva: International Organization for Standardization; 1995.

91. Schreer JF, Kovacs KM. Allometry of diving capacity in air-breathing vertebrates. Can J Zool. 1997;75:339-58.

92. Kendrick S. Vessels to withstand external pressure, pp 197-233 (Chapter 6). In: Nichols RW, editor. Developments in pressure vessel technology, vol. 4: designs for specific applications. London: Elsevier; 1983. p. 325.

93. Faulkner D, Dast PK. Application of reliability theory to structural design and assessment of submarines and other externally pressurised cylindrical structures. In: Faulkner D, Cowling MJ, Incecik A, editors. Integrity of offshore structures. London: Spon Press; 1991. p. 199-230.
94. Owens BB, editor. Batteries for implantable biomedical devices. New York: Plenum Press; 1986. p. 357p.

95. Mulcahy DM. Surgical implantation of transmitters into fish. ILAR J. 2003;44(4):295-306.

96. Flecknell PA. Animal pain—an introduction. In: Flecknell PA, WatermanPearson A, editors. Pain management in animals. London: W.B. Saunders; 2000. p. 1-7.

97. Dobromylskyj P, Flecknell PA, Lascelles BD, Livingston A, Taylor P, Waterman-Pearson A. Management of postoperative and other acute pain; pp. In: Flecknell PA, Waterman-Pearson A, editors. Pain management in animals. London: W.B. Saunders; 2000. p. 81-145.

98. Delport TC, Harcourt RG, Beaumont LJ, Webster KN, Power ML. Molecular detection of antibiotic-resistance determinants in Escherichia coli isolated from the endangered Australian sea lion (Neophoca cinerea). J Wildl Dis. 2015;51(3):555-63.

99. Baily JL, Foster G, Brown D, Davison NJ, Coia JE, Watson E, Pizzi R, Willoughby K, Hall AJ, Dagleish MP. Salmonella infection in grey seals (Halichoerus grypus), a marine mammal sentinel species: pathogenicity and molecular typing of Salmonella strains compared with human and livestock isolates. Environ Microbiol. 2016;18(3):1078-87.

100. Wilson RP, McMahon CR. Measuring devices on wild animals: What constitutes acceptable practice? Front Ecol Environ. 2006:4:147-54.

101. Dickens MJ, Delahanty DJ, Romero LM. Stress and translocation: alterations in the stress physiology of translocated birds. Proc R Soc. 2009;B276:2051-6.

102. Parker KA, Dickens MJ, Clarke $\mathrm{RH}$. The theory and practice of catching, holding, moving and releasing animals. P112-137. In: Ewen JG, Armstrong DP, Parker KA, Seddon PJ, editors. Reintroduction biology: integrating science and management. London: Wiley; 2010. p. 112-37.

\section{Submit your next manuscript to BioMed Central and we will help you at every step:}

- We accept pre-submission inquiries

- Our selector tool helps you to find the most relevant journal

- We provide round the clock customer support

- Convenient online submission

- Thorough peer review

- Inclusion in PubMed and all major indexing services

- Maximum visibility for your research

Submit your manuscript at www.biomedcentral.com/submit 